\title{
First Record of Orobdella tsushimensis (Hirudinida: Arhynchobdellida: Gastrostomobdellidae) from the Korean Peninsula and Molecular Phylogenetic Relationships of the Specimens
}

\author{
Takafumi Nakano,*, Hong-Yul Seo ${ }^{2}$ \\ 'Department of Zoology, Graduate School of Science, Kyoto University, \\ Kyoto 606-8502, Japan \\ ${ }^{2}$ National Institute of Biological Resources, Incheon 404-708, Korea
}

\begin{abstract}
Specimens of the genus Orobdella Oka, 1895 from Korea, including various locations in the Korean Peninsula, were identified as Orobdella tsushimensis Nakano, 2011. Phylogenetic analyses using mitochondrial cytochrome oxidase subunit 1 (COI), ND1, tRNA ${ }^{\text {Cys }}$, tRNA ${ }^{\mathrm{Met}}, 12 \mathrm{~S}$ rRNA, tRNA ${ }^{\mathrm{val}}$, and 16S rRNA markers show that the newly collected specimens form a monophyletic group with the known $O$. tsushimensis specimens. The genetic distance of COI of these specimens was in the range $0.4-6.6 \%$. These results confirm that the newly collected specimens belong to O. tsushimensis. This is the first record of the genus Orobdella from the Korean Peninsula.
\end{abstract}

Keywords: Hirudinida, Gastrostomobdellidae, Orobdella tsushimensis, molecular phylogeny, first record, Korean Peninsula

\section{NTRODUCTI ON}

The genus Orobdella Oka, 1895 is a terrestrial macrophagous leech taxon that is distributed in the Far East. At present 11 species of this genus have been described: 10 from Japan (Oka, 1895; Richardson, 1975; Nakano, 2010, 2011a, 2011b, 2012a, 2012b, 2012c); and the other from Taiwan (Nakano and Lai, 2012). Additionally, Orobdella whitmani Oka, 1895 has been reported from Primorsky Krai, Russia (Gilyarov et al., 1969), but the precise taxonomic status of the Russian specimens still remains uncertain (Nakano, 2012b). Yun (1997) provided a Korean leech list, but Orobdella leeches were not included in this list. Recently, quadrannulate Orobdella tsushimensis Nakano, 2011 has been recorded from Gageodo Island, which is located in the Yellow Sea, southwest of the Korean Peninsula (Nakano and Seo, 2012). However, Orobdella leeches have never been reported from the Korean Peninsula.

Recently, additional specimens of the quadrannulate Orobdella were collected from various places in Korea, including locations in the Korean Peninsula. This is the first record of the genus Orobdella from the peninsula. The identification and a description of the newly collected specimens are herein presented. In addition, their phylogenetic relationships are reconstructed using mitochondrial cytochrome oxidase subunit 1 (COI), ND1, tRNA ${ }^{\text {Cys }}$, tRNA ${ }^{\text {Met }}, 12 \mathrm{~S}$ rRNA, tRNA ${ }^{\mathrm{val}}$, and 16S rRNA (tRNA ${ }^{\text {Cys }}$-16S) sequence data.

\section{MATERI ALS AND METHODS}

Leeches were collected from various places in Korea (Fig. 1). Altitudes and coordinates for localities were obtained using a Garmin eTrex GPS unit.

For DNA extraction, botryoidal tissue was taken from the posterior part of the body around the caudal sucker of the specimens. All of the specimens were preserved in $70 \%$ ethanol. Four measurements were taken: body length (BL) from the anterior margin of the oral sucker to the posterior margin of the caudal sucker; maximum body width (BW); caudal

(c) This is an Open Access article distributed under the terms of the Creative Commons Attribution Non-Commercial License (http://creativecommons.org/ licenses/by-nc/3.0/) which permits unrestricted non-commercial use, distribution, and reproduction in any medium, provided the original work is properly cited.

pISSN 2234-6953 eISSN 2234-8190

*To whom correspondence should be addressed

Tel: 81-75-753-4091, Fax: 81-75-753-4114

E-mail: nakano@zoo.zool.kyoto-u.ac.jp 

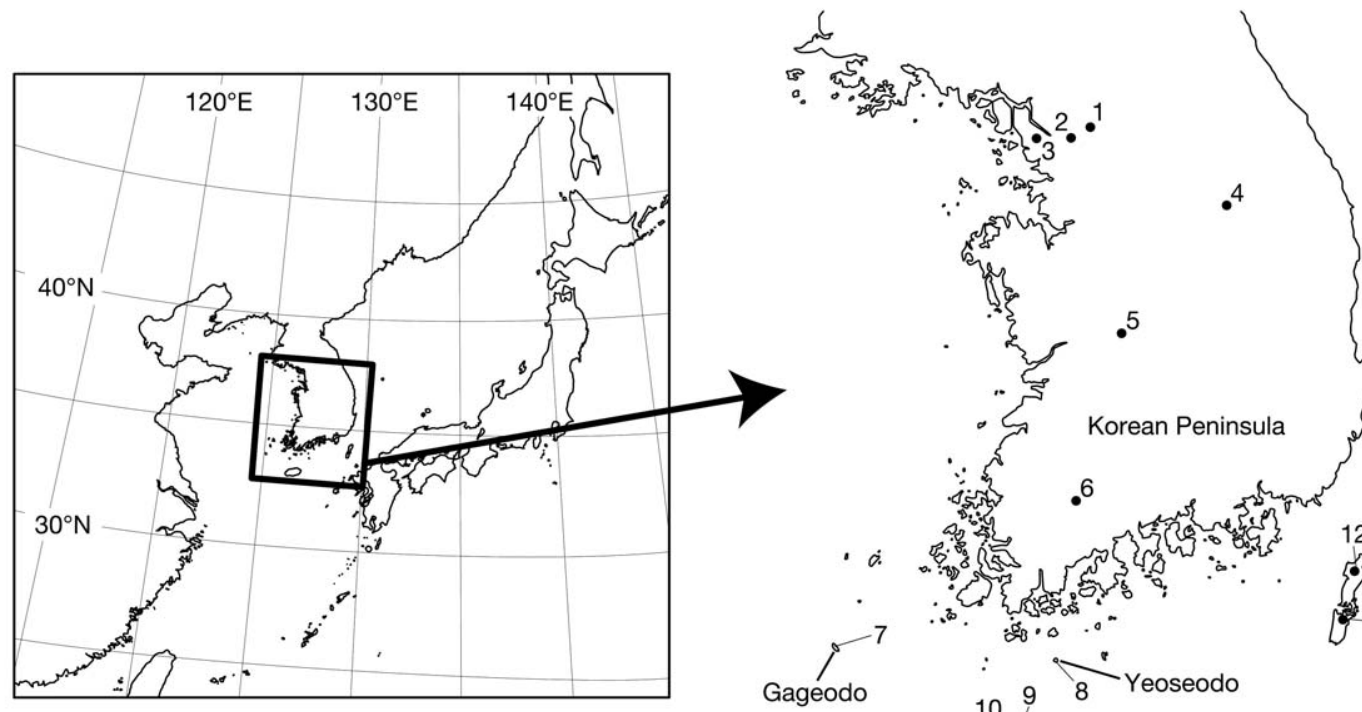

$100 \mathrm{~km}$

Fig. 1. Map showing the collection localities of the specimens examined in this study (nos. 1-11), Tsushima Island, Japan, and the type locality of Orobdella tsushimensis Nakano, 2011.

sucker length (CL) from the anterior to the posterior margin of the sucker; caudal sucker width $(\mathrm{CW})$ from the right margin to the left margin of the sucker. Examination, dissection, and drawings of the specimens were accomplished using a stereoscopic microscope equipped with a drawing tube (Leica M125; Leica, Wetzlar, Germany). Specimens used in this study have been deposited in the Zoological Collection of Kyoto University (KUZ).

The numbering convention is based on Moore (1927): body somites are denoted by Roman numerals and the annuli in each somite are given alphanumeric designations.

The extraction of genomic DNA and DNA sequencing methods for COI and tRNA ${ }^{\mathrm{Cys}}$-16S followed Nakano (2012b). For obtaining tRNA ${ }^{\text {Leu }}$ and ND1 (tRNA ${ }^{\text {Leu }}$-ND1) sequence data, the procedure above was modified as follows: the primer sets for tRNA ${ }^{\text {Leu }}$-ND1 were LND300 and HND1932 (Light and Siddall, 1999) or HND1932-in (5'-AATGGAGCACGA TTAGTTTC- $3^{\prime}$ ) (in this study); the PCR reaction mixture for tRNA ${ }^{\text {Leu }}$-ND1 was heated to $94^{\circ} \mathrm{C}$ for $5 \mathrm{~min}$, followed by 35 cycles of $94^{\circ} \mathrm{C}(10 \mathrm{~s}), 45^{\circ} \mathrm{C}(20 \mathrm{~s})$, and $72^{\circ} \mathrm{C}(39 \mathrm{~s})$ and a final extension at $72^{\circ} \mathrm{C}$ for $6 \mathrm{~min}$; the sequencing reaction mixture for tRNA ${ }^{\text {Leu }}$-ND1 was incubated at $96^{\circ} \mathrm{C}$ for $2 \mathrm{~min}$, followed by 40 cycles of $96^{\circ} \mathrm{C}(10 \mathrm{~s}), 50^{\circ} \mathrm{C}(5 \mathrm{~s})$, and $60^{\circ} \mathrm{C}$ (39 s). Obtained sequences have been deposited in GenBank. Sequences used for molecular phylogenetic analyses are listed in Table 1; 16 sequences of COI, 3 those of tRNA ${ }^{\text {Leu }}$ ND1 and 15 those of tRNA ${ }^{\text {Cys }}-16 S$, which were published in the previous studies (Nakano, 2012a, 2012b; Nakano and
Lai, 2012; Nakano and Seo, 2012; Nakano and Gongalsky, 2014), were obtained from GenBank.

Sequences of mitochondrial COI and ND1 (tRNA ${ }^{\text {Leu }}$ region was removed from each sequence) were aligned by eye because there were no indels. Mitochondrial tRNA ${ }^{\text {Cys }}-16 \mathrm{~S}$ sequences were aligned using MAFFT L-INS-I (Katoh et al., 2005) and then refined with GBLOCKS (Castresana, 2000). The length of the aligned COI sequences was 1,266 bp, that of ND1 was $579 \mathrm{bp}$, and that of tRNA ${ }^{\text {Cys }}-16 \mathrm{~S}$ was $818 \mathrm{bp}$ (288 characters were eliminated). The concatenated sequences thus yielded a total of 2,663 bp positions. Pairwise comparisons of Kimura-2 parameter (K2P) distance (Kimura, 1980) of the COI sequences were calculated using MEGA5 (Tamura et al., 2011).

Phylogenetic trees were constructed using maximum likelihood (ML) and Bayesian inference (BI) models. ML phylogenies were calculated using TREEFINDER v October 2008 (Jobb et al., 2004) with the tool package PHYLOGEARS v 2.0 (Tanabe, 2008), and then nonparametric bootstrapping (Felsenstein, 1985) was conducted with 500 replicates. The best-fit models for each partition were selected based on the Akaike Information Criterion (Akaike, 1974) by using KAKUSAN4 (Tanabe, 2011): for the 1st position of COI, TN93 with gamma distribution $(+\mathrm{G})$ and proportion of invariant sites $(+\mathrm{I})$; for the 2nd position of $\mathrm{COI}, \mathrm{TVM}+\mathrm{I}$; for the $3 \mathrm{rd}$ position of $\mathrm{COI}, \mathrm{HKY} 85+\mathrm{G}$; for the 1st position of ND1, GTR $+\mathrm{G}+\mathrm{I}$; for the 2nd position of $\mathrm{ND} 1, \mathrm{~J} 1+\mathrm{G}$; for the $3 \mathrm{rd}$ position of ND1, J2 $+\mathrm{G}$; and for 
Orobdella from Korean Peninsula

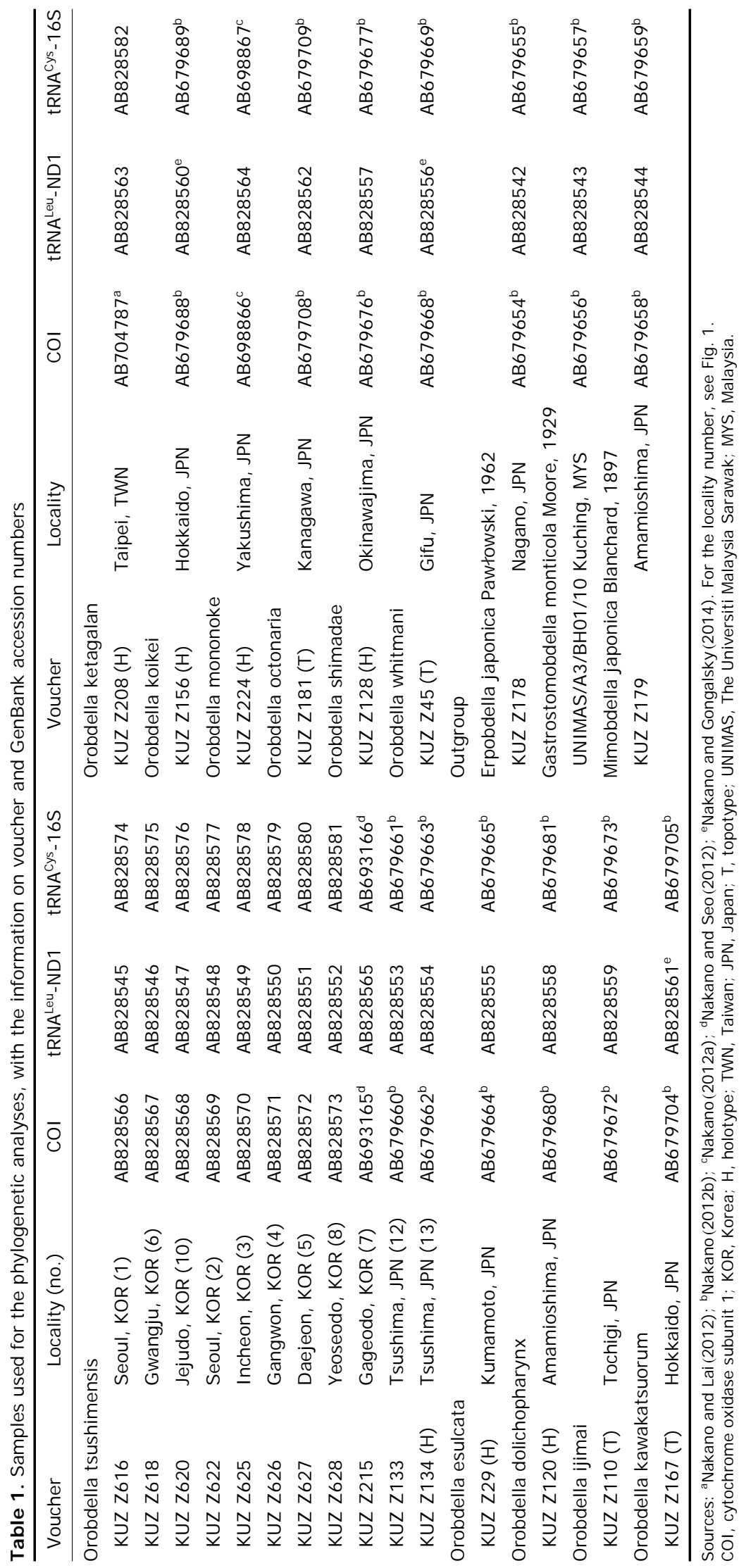




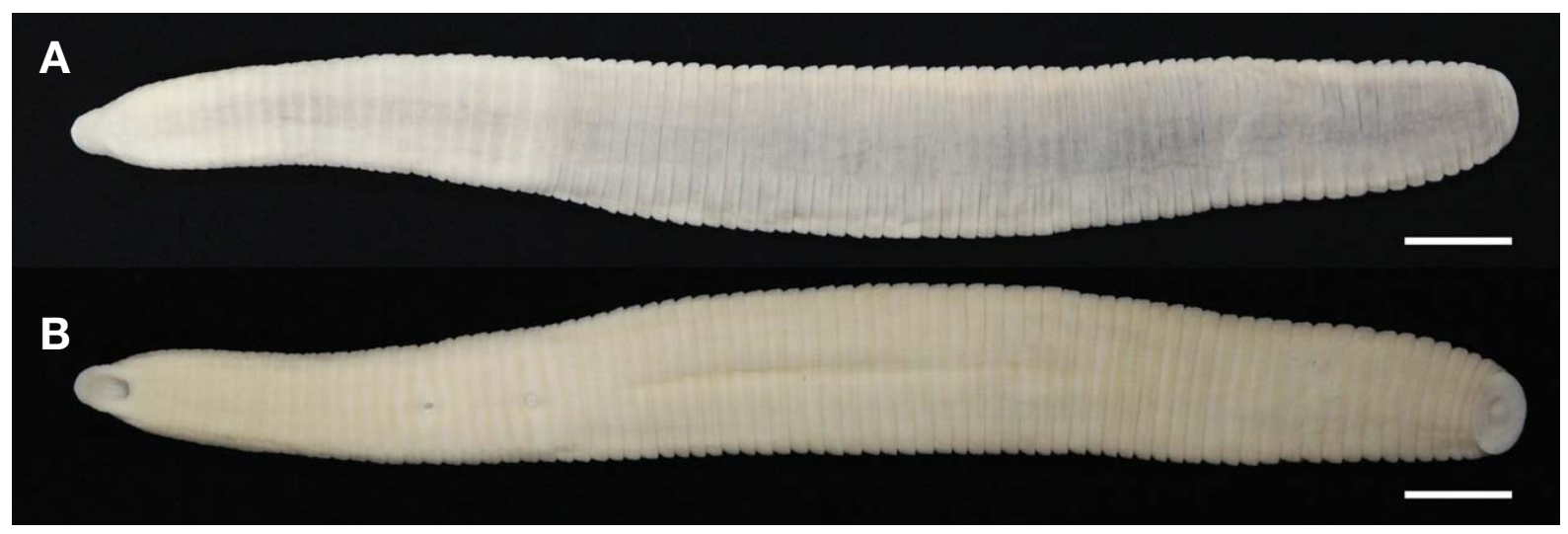

Fig. 2. Orobdella tsushimensis Nakano, 2011 from Seoul, KUZ Z616. A, Dorsal view; B, Ventral view. Scale bars: A, B=5 mm.

tRNA ${ }^{\text {Cys }}-16 \mathrm{~S}, \mathrm{GTR}+\mathrm{G}$ was selected. BI and Bayesian posterior probabilities (BPPs) were estimated using MRBAYES v 3.2 (Ronquist et al., 2012). The best-fit models for each partition were identified under the Bayesian information criterion (Schwarz, 1978) and also by using KAKUSAN4: for the 1 st position of $\mathrm{COI}, \mathrm{GTR}+\mathrm{G}+\mathrm{I}$; for the $2 \mathrm{nd}$ position of $\mathrm{COI}, \mathrm{F} 81+\mathrm{I}$; for the 3 rd position of COI, HKY85+G; for the 1st position of ND1, GTR $+\mathrm{G}+\mathrm{I}$; for the 2nd position of ND1, HKY85+G; for the 3rd position of ND1, HKY85+G; and for tRNA ${ }^{\text {Cys }}-16 \mathrm{~S}$, GTR $+\mathrm{G}$ was selected. Two independent runs of four Markov chains were conducted for 4 million generations, and the tree was sampled every 100 generations. The parameter estimates and convergence were checked using TRACER v 1.5 (Rambaut and Drummond, 2009), and based on these results, the first 10,001 trees were discarded.

Nodes with bootstrap (BS) values higher than $70 \%$ were considered as sufficiently resolved (Hillis and Bull, 1993). Nodes with BPPs higher than $95 \%$ were considered statistically significant (Leaché and Reeder, 2002).

\section{SYSTEMATI C ACCOUNTS}

Order Arhynchobdellida Blanchard, 1894

Suborder Erpobdelliformes Sawyer, 1986

1*Family Gastrostomobdellidae Richardson, 1971

${ }^{2 *}$ Genus Orobdella Oka, 1895

3*Orobdella tsushimensis Nakano, 2011 (Figs. 2, 3)

Orobdella tsushimensis Nakano, 2011a: 41-46, figs. 2-4

(near the Orobashi Bridge at Kechi Dam, alt. $69 \mathrm{~m}, 34^{\circ}$ $15^{\prime} 17^{\prime \prime} \mathrm{N}, 129^{\circ} 17^{\prime} 17^{\prime \prime} \mathrm{E}$, Tsushima, Tsushima Island, Naga- saki Prefecture, Japan, holotype, KUZ Z134); Nakano and Seo, 2012: 237-239, figs. 2-4.

Material examined (see Fig. 1 for the locality number). Korea: 3 specimens, Seoul: Nowon-gu, Mt. Suraksan, alt. $118 \mathrm{~m}, 37^{\circ} 41^{\prime} 08^{\prime \prime} \mathrm{N}, 127^{\circ} 04^{\prime} 07^{\prime \prime} \mathrm{E}$ (locality no. 1), 4 Jul 2012, Seo HY, KUZ Z615, Z616, dissected, and KUZ Z617; 2 specimens, Jongno-gu, Mt. Bukhansan, alt. $447 \mathrm{~m}, 37^{\circ} 37^{\prime}$ $28^{\prime \prime} \mathrm{N}, 126^{\circ} 57^{\prime} 41^{\prime \prime} \mathrm{E}$ (locality no. 2), 6 Jul 2012, Seo HY, KUZ Z621 and Z622, dissected; 2 specimens, Jeollanamdo: Sinan-gun, Gageodo Island, alt. $429 \mathrm{~m}, 34^{\circ} 04^{\prime} 49^{\prime \prime} \mathrm{N}$, $125^{\circ} 96^{\prime} 27^{\prime \prime}$, (locality no. 7), 10 Jul 2012, Seo HY, KUZ Z623 and Z624; 1 specimen, Wando-gun, Yeoseodo Island, alt. $46 \mathrm{~m}, 33^{\circ} 59^{\prime} 03^{\prime \prime} \mathrm{N}, 126^{\circ} 55^{\prime} 19^{\prime \prime} \mathrm{E}$ (locality no. 8), $20 \mathrm{Jul}$ 2012, Seo HY, KUZ Z628, dissected; 1 specimen, Jejudo Island: Jeju-si, alt. $384 \mathrm{~m}, 33^{\circ} 26^{\prime} 47^{\prime \prime} \mathrm{N}, 126^{\circ} 33^{\prime} 49^{\prime \prime} \mathrm{E}$ (locality no. 9), 17 Jun 2012, Seo HY, KUZ Z614; 1 specimen, Seogwipo-si, alt. $183 \mathrm{~m}, 33^{\circ} 18^{\prime} 05^{\prime \prime} \mathrm{N}, 126^{\circ} 37^{\prime} 51^{\prime \prime} \mathrm{E}$ (locality no. 11), 27 Sep 2012, Seo HY, KUZ Z629; 1 specimen, Jejusi, Mt. Hanlasan, alt. 1,601 m, 33 $21^{\prime} 56^{\prime \prime} \mathrm{N}, 126^{\circ} 30^{\prime} 48^{\prime \prime} \mathrm{E}$ (locality no. 10), 2 Jul 2012, Kang SG, KUZ Z620, dissected; 1 specimen, Gwangju Metropolitan City: Dong-gu, Mt. Mudeungsan, alt. $533 \mathrm{~m}, 35^{\circ} 07^{\prime} 11^{\prime \prime} \mathrm{N}, 126^{\circ} 58^{\prime} 56^{\prime \prime} \mathrm{E}$ (locality no. 6), 1 Jul 2012, Seo HY, KUZ Z618, dissected; 1 specimen, Dong-gu, Mt. Mudeungsan, alt. $375 \mathrm{~m}, 35^{\circ} 07^{\prime} 21^{\prime \prime} \mathrm{N}$, $126^{\circ} 58^{\prime} 34^{\prime \prime}$ E (locality no. 6), 24 Jun 2012, Seo HY, KUZ Z619; 1 specimen, Incheon Metropolitan City: Gyeyang-gu,

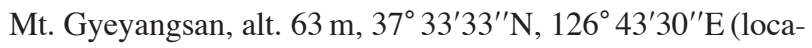
lity no. 3), 11 Oct 2012, Seo HY, KUZ Z625, dissected; 1 specimen, Gangwon-do: Wonju-si, Mt. Chiaksan, alt. 790 m, $37^{\circ} 18^{\prime} 07^{\prime \prime} \mathrm{N}, 128^{\circ} 03^{\prime} 39^{\prime \prime} \mathrm{E}$ (locality no. 4), 5 Oct 2012 , Seo HY, KUZ Z626, dissected; 1 specimen, Daejeon Metropolitan City: Seo-gu, Mt. Changtaesan, alt. 245 m, 36 $11^{\prime} 38^{\prime \prime} \mathrm{N}$,

Korean name: ${ }^{*}$ 왕산거머리과, ${ }^{2 *}$ 왕산거머리속, ${ }^{3 *}$ 왕산거머리 

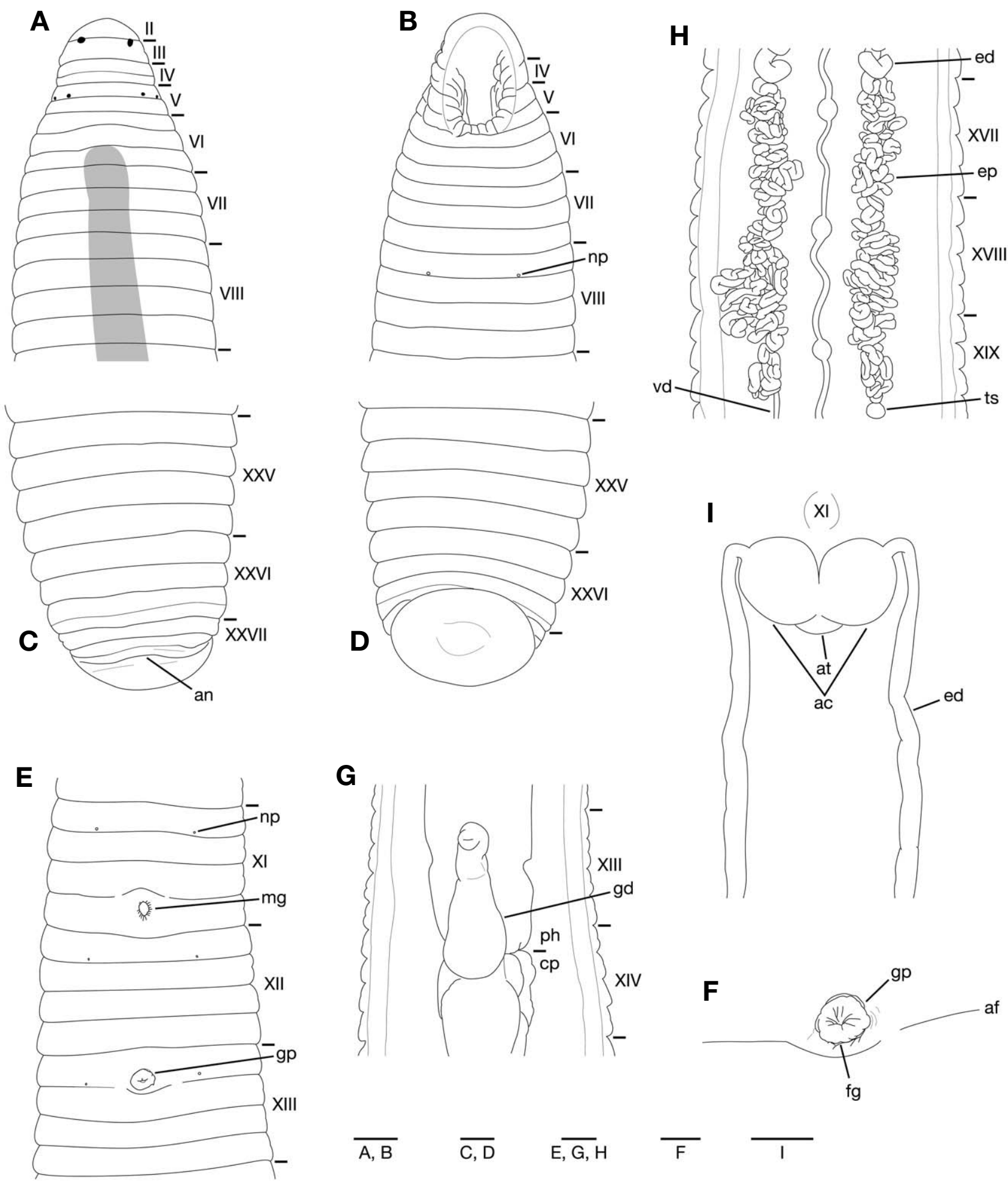

Fig. 3. Orobdella tsushimensis Nakano, 2011 from Seoul, KUZ Z616. A, Dorsal view of somites I-VIII; B, Ventral view of somites IVIII; C, Dorsal view of somites XXV-XXVII and caudal sucker; D, Ventral view of somites XXV-XXVII and caudal sucker; E, Ventral view of somites XI-XIII; F, Ventral view of gastropore and female gonopore; G, Ventral view of gastroporal duct; $H$, Dorsal view of epididymides and ventral nervous system; I, Dorsal view of male atrium showing position of ganglion XI. ac, atrial cornua; af, annular furrow; an, anus; at, atrium; cp, crop; ed, ejaculatory duct; ep, epididymis; fg, female gonopore; gd, gastroporal duct; gp, gastropore; mg, male gonopore; $n p$, nephridiopore; ph, pharynx; ts, testisac; vd, vas deferens. Scale bars: $A-E, G-I=1 \mathrm{~mm}, F=0.5$ $\mathrm{mm}$. 
$127^{\circ} 20^{\prime} 19^{\prime \prime} \mathrm{E}$ (locality no. 5), 5 Oct 2012, Seo HY, KUZ Z627, dissected.

Description. Maximum BL 105.4 mm (KUZ Z622), BW 11.9 mm (KUZ Z628), minimum BL 33.2 (KUZ Z626), BW $4.3 \mathrm{~mm}$ (KUZ Z619). Caudal sucker ventral, ellipsoid, maximum CL $3.9 \mathrm{~mm}$, CW $6.6 \mathrm{~mm}$ (KUZ Z622), minimum CL $1.6 \mathrm{~mm}$ (KUZ Z624), CW $2.0 \mathrm{~mm}$ (KUZ Z626).

Somites VIII-XXV quadrannulate, somite XXVI triannulate (Fig. 3A-E). Anus behind somite XXVII with no postanal annulus (Fig. 3C). Clitellum in XI b5 to XIII a2. Eyes often in 3 pairs, first pair dorsally in posterior margin of II, second and third pairs dorsolaterally in posterior margin of $\mathrm{V}(\mathrm{a} 1+\mathrm{a} 2)$ (Fig. 3A). Nephridiopores in 17 pairs in VIIIXXIV (Fig. 3B, E).

Pharynx reaching to XIII b5/b6-XIV b6 (Fig. 3G); each pharyngeal ridges reaching to crop straightly. Crop tubular, reaching to XIX b5/b6-XX a1/a2. Gastropore conspicuous in XIII a1/a2 (Fig. 3E, F). Gastroporal duct developed, bulbous, or bottle-shaped, slightly winding at junction with gastropore; joining with crop in XIII b6-XIV b6 (Fig. 3G).

Male gonopore in XI b6 (slightly anterior to middle of annulus), female gonopore inconspicuous in XIII a1/a2, behind gastropore, gonopores separated by $1 / 2+5$ annuli (Fig. 3E, F). Testisacs multiple, in XVIII b5-XX b6 to XXIV a1XXVb6 (Fig. 3H). Paired epididymides in XV b5-XVIII a1/a2 to XVIII b5-XX a1/a2 (Fig. 3H). Ejaculatory ducts in XI b5 to $\mathrm{XV}$ b5-XVIII a1/a2; nearly straight in position anterior to ovisacs (Fig. 3I); coiled in position posterior to ovisacs (Fig. 3H). Pair of muscular atrial cornua, ovate in XI b5 and b6 (Fig. 3I) or fusiform in XI b6. Atrium short, muscular, globular, in XI b5 and b6. One pair of ovisacs, thin-walled, globular, in XIII a2 and b5. Oviducts thin-walled, both oviducts converging into common oviduct in XIII a2.

Distribution. Known from mountainous regions of the Korean Peninsula and its peripheral islands including Tsushima Island, Japan (Nakano, 2011a; Nakano and Seo, 2012).

Phylogenetic relationships (see Fig. 1 for the locality number). The ML tree with $\ln L=-17134.56$ (Fig. 4) was identical in topology to the obtained BI tree (not shown). Monophyly of the genus Orobdella was confirmed (BS $=100 \%$, $\mathrm{BPP}=100 \%$ ). Although O. tsushimensis formed a monophyletic lineage with the clade that consists of ([O. esulcata Nakano, 2010+O. mononoke Nakano, 2012] $+[$ O. ketagalan Nakano and Lai, $2012+\{$ O. dolichopharynx Nakano, 2011+O. shimadae Nakano, 2011\}]), the phylogenetic position of $O$. tsushimensis was not statistically resolved $(\mathrm{BS}=45 \%, \mathrm{BPP}=$ $86 \%)$.

Monophyly of $O$. tsushimensis was confirmed (BS $=100 \%$, $\mathrm{BPP}=100 \%$ ). Within $O$. tsushimensis, three lineages were recognized and defined. Lineage A contained only KUZ Z626 from Mt. Chiaksan, Gwangwon (locality no. 4). Lineage B consisted only of KUZ Z627 from Mt. Changtaesan, Daejeon (no. 5). Lineage $C$ consisted of the other nine specimens. Lineages $\mathrm{B}$ and $\mathrm{C}$ formed a monophyletic lineage

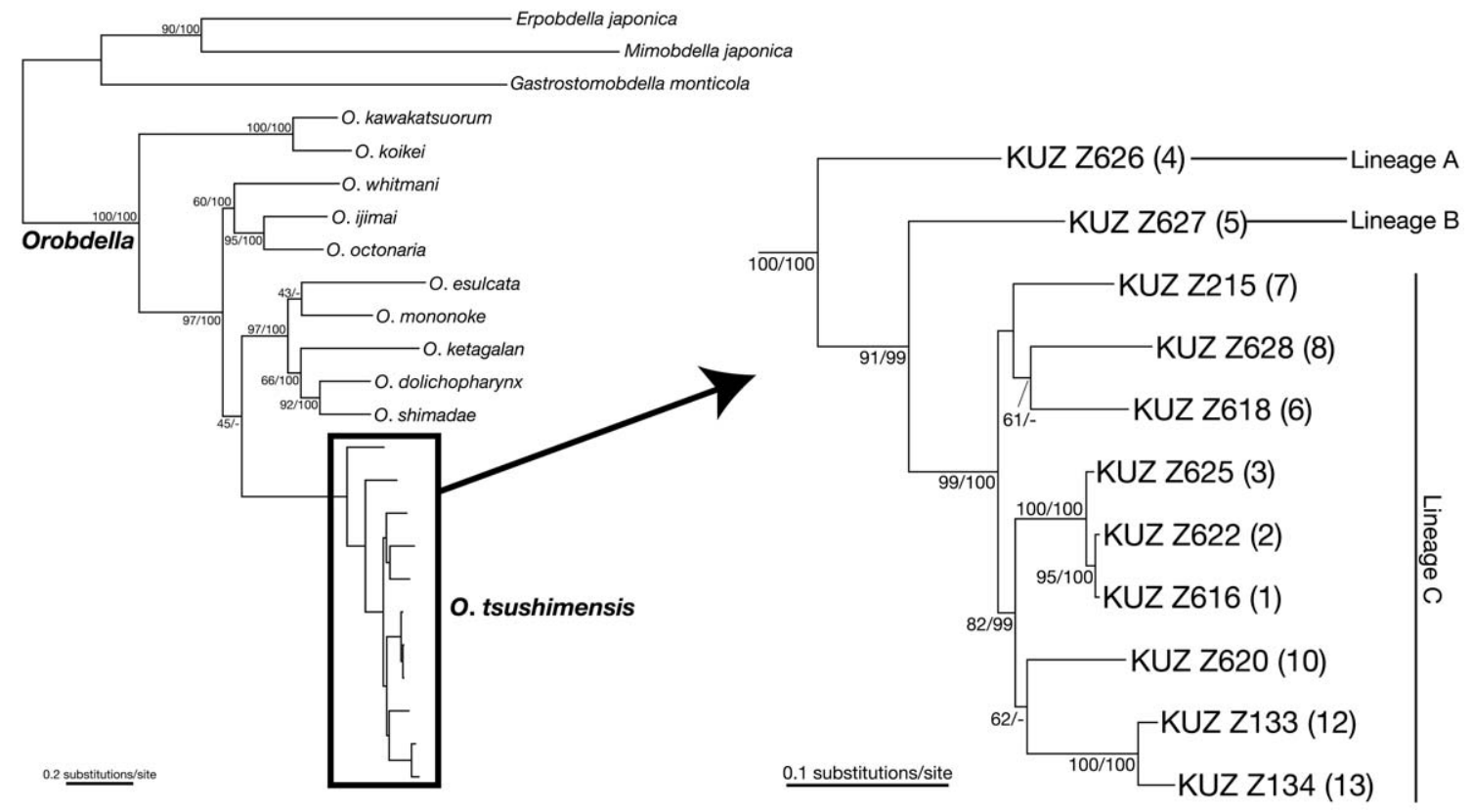

Fig. 4. The maximum likelihood (ML) tree of 2,663 bp of cytochrome oxidase subunit 1 (COI), ND1, tRNA ${ }^{\text {Cys }}$, tRNA ${ }^{\text {Met }}, 12 S$ rRNA, tRNA ${ }^{\text {val }}$, and 16S rRNA. The numbers associated with the nodes represent bootstrap values for ML (BS)/and Bayesian posterior probabilities (BPPs). BSs higher than 40\% and/or BPPs higher than $95 \%$ are indicated. For the locality number, see Fig. 1 and Table 1. 
(BS=91\%, BPP=99\%). Within Lineage C, a monophyletic lineage $(\mathrm{BS}=100 \%, \mathrm{BPP}=100 \%)$ of three specimens, KUZ Z616 (no. 1), Z622 (no. 2) and Z625 (no. 3) from around Seoul, KUZ Z620 from Jejudo Island (no. 10) and a monophyletic lineage $(\mathrm{BS}=100 \%, \mathrm{BPP}=100 \%)$ of two specimens, KUZ Z133 (no. 12) and Z134 (no. 13), from Tsushima Island formed a monophyletic lineage $(B S=82 \%, B P P=99 \%)$. KUZ Z215 (no. 7), Z618 (no. 6) and Z628 (no. 8) from the southwestern part of Korea, including Gageodo and Yeoseodo Islands, also formed a monophyletic lineage, but with low support values $(\mathrm{BS}=37 \%, \mathrm{BPP}=58 \%)$.

Genetic divergence. The COI K2P distance within $O$. $t s u$ shimensis was between $0.4-6.6 \%$ (mean $=5.0 \%$ ).

Remarks. The present specimens newly collected from various places in Korea clearly belong to O. tsushimensis based on their possession of the following characteristics: somites VIII-XXV quadrannulate; gastropore conspicuous in XIII a1/a2; gastroporal duct developed, bulbous; male gonopore in middle of XI b6, female gonopore in XIII a1/a2, behind gastropore, gonopores separated by $1 / 2+5$ annuli; paired epididymides in $\mathrm{XV}-\mathrm{XX}$, occupying more than 2 somites; atrial cornua developed, ovate or conical. One specimen, KUZ Z627, possesses tubular gastroporal duct and fusiform atrial cornua. However, these characteristics of this specimen seemed to be due to its immaturity, since this individual has undeveloped sperm ducts and undetectable testisacs. In Nakano and Seo (2012), O. tsushimensis has been diagnosed as having epididymides in XVII-XIX (occupying approximately 2 somites). However, the present specimens have their epididymides in somites $\mathrm{XV}-\mathrm{XX}$ (occupying 8-12 annuli, i.e., 23 somites). Therefore, the diagnosis in Nakano and Seo (2012) should be amended to take this difference into account.

The molecular phylogenies obtained here showed that the specimens that were morphologically identified as $O$. tsushimensis form a well-supported monophyletic group. Additionally, the COI sequence divergence within these specimens was between $0.4-6.6 \%$ (mean $=5.0 \%$ ). For comparison, the intraspecific variation of COI sequences of $O$. koikei in Hokkaido, Japan was between $4.8-8.1 \%$ (mean=7.1\%) (Nakano, 2012b). Thus, our molecular phylogenetic analyses and genetic distance data strongly support our morphological identification result that the Orobdella leeches newly collected in this study belong to $O$. tsushimensis.

The present molecular phylogenies showed that the specimen from Mt. Chiaksan (Lineage A; locality no. 4) first diverged from the others. Then, the specimen from Mt. Changtaesan (Lineage B; no. 5) diverged from the other leeches. It is noteworthy that the specimen from Jejudo Island (no. 10) and two specimens from Tsushima Island (nos. 12, 13) are monophyletic, which was statistically supported, with the three specimens from locations around Seoul (nos. 1-3), not with the specimens from adjacent localities (i.e., nos. 68 ). This geographic pattern of the phylogenetic relationships suggests a complex biogeographical history of O. tsushimensis. However, the present phylogenies failed to reconstruct fully robust phylogenetic relationships within Lineage $\mathrm{C}$. Additional specimens of $O$. tsushimensis as well as suitable genetic markers are still needed to clarify the precise phylogenetic relationships and biogeographical history of this species.

\section{ACKNOWLEDGMENTS}

The authors are grateful to Professor Tsutomu Hikida (Kyoto University; KU) for his helpful comments and suggestions to improve this manuscript. We are also grateful to Dr. Seung$\mathrm{Gu}$ Kang (National Institute of Biological Resources) for providing the Orobdella specimen from Jejudo Island, to three anonymous reviewers for their constructive comments on the manuscript, and to Dr. Elizabeth Nakajima (KU) for checking the English of this text. A part of this study was financially supported by Grants for Biodiversity and Evolutionary Research of Global COE (A06) and for Excellent Graduate Schools, both from MEXT, Japan, to Kyoto University, National Institute of Biological Resources, Ministry of Environment, the Republic of Korea, and a JSPS Research Fellowship for Young Scientists to TN.

\section{REFERENCES}

Akaike H, 1974. A new look at the statistical model identification. IEEE Transactions on Automatic Control, 19:716 723.

Castresana J, 2000. Selection of conserved blocks from multiple alignments for their use in phylogenetic analysis. Molecular Biology and Evolution, 17:540-552.

Felsenstein J, 1985. Confidence limits on phylogenies: an approach using the bootstrap. Evolution, 39:783-791.

Gilyarov MS, Lukin EI, Perel TS, 1969. The first terrestrial leechOrobdella whitmani Oka (Hirudinel, Herpobdellidae) in the fauna of the USSR: A Tertiary relict of forests of the southern Maritime Territory. Doklady Akademii Nauk SSSR, 188:235-237 (in Russian).

Hillis DM, Bull JJ, 1993. An empirical test of bootstrapping as a method for assessing confidence in phylogenetic analysis. Systematic Biology, 42:182-192.

Jobb G, von Haeseler A, Strimmer K, 2004. TREEFINDER: a powerful graphical analysis environment for molecular phylogenetics. BMC Evolutionary Biology, 4:18.

Katoh K, Kuma K, Toh H, Miyata T, 2005. MAFFT version 5: improvement in accuracy of multiple sequence alignment. Nucleic Acids Research, 33:511-518. 
Kimura M, 1980. A simple method for estimating evolutionary rates of base substitutions through comparative studies of nucleotide sequences. Journal of Molecular Evolution, 16: 111-120.

Leaché AD, Reeder TW, 2002. Molecular systematics of the eastern fence lizard (Sceloporus undulatus): a comparison of parsimony, likelihood, and Bayesian approaches. Systematic Biology, 51:44-68.

Light JE, Siddall ME, 1999. Phylogeny of the leech family Glossiphoniidae based on mitochondrial gene sequences and morphological data. The Journal of Parasitology, 85:815-823.

Moore JP, 1927. The segmentation (metamerism and annulation) of the Hirudinea. In: The Fauna of British India, including Ceylon and Burma. Hirudinea (Eds., Harding WA, Moore JP). Taylor \& Francis, London, pp. 1-12.

Nakano T, 2010. A new species of the genus Orobdella (Hirudinida: Arhynchobdellida: Gastrostomobdellidae) from Kumamoto, Japan, and a redescription of $O$. whitmani with the designation of the lectotype. Zoological Science, 27:880-887.

Nakano T, 2011a. A new species of Orobdella (Hirudinida: Arhynchobdellida: Gastrostomobdellidae) from Tsushima Island, Japan. Species Diversity, 16:39-47.

Nakano T, 2011b. Redescription of Orobdella ijimai (Hirudinida: Arhynchobdellida: Gastrostomobdellidae), and two new species of Orobdella from the Ryukyu Archipelago, Japan. Zootaxa, 2998:1-15.

Nakano T, 2012a. A new sexannulate species of Orobdella (Hirudinida, Arhynchobdellida, Orobdellidae) from Yakushima Island, Japan. ZooKeys, 181:79-93.

Nakano T, 2012b. A new species of Orobdella (Hirudinida, Arhynchobdellida, Gastrostomobdellidae) and redescription of Orobdella kawakatsuorum from Hokkaido, Japan with the phylogenetic position of the new species. ZooKeys, 169: 9-30.

Nakano T, 2012c. Redescription of Orobdella octonaria (Hirudinida: Arhynchobdellida: Orobdellidae) with designation of a lectotype. Species Diversity, 17:227-233.

Nakano T, Gongalsky KB, 2014. First record of Orobdella kawakatsuorum (Hirudinida: Arhynchobdellida: Erpobdelliformes) from Kunashir Island, Kuril Islands. Biodiversity Data Journal, 2:e1058.

Nakano T, Lai YT, 2012. A new species of Orobdella (Hirudinida, Arhynchobdellida, Orobdellidae) from Taipei, Taiwan.
ZooKeys, 207:49-63.

Nakano T, Seo HY, 2012. First record of Orobdella tsushimensis (Hirudinida: Arhynchobdellida: Orobdellidae) from Korea (Gageodo Island) and its molecular phylogenetic position within the genus. Species Diversity, 17:235-240.

Oka A, 1895. On some new Japanese land leeches (Orobdella nov. gen.). The Journal of the College of Science, Imperial University, Japan, 8:275-306.

Rambaut A, Drummond AJ, 2009. Tracer v 1.5 [Internet]. Andrew Rambaut, Accessed 20 Jun 2013, <http://ree.bio.ed. ac.uk/software/tracer/>.

Richardson LR, 1975. A new species of terricolous leeches in Japan (Gastrostomobdellidae, Orobdella). Bulletin of the National Science Museum Series A (Zoology), 1:39-56.

Ronquist F, Teslenko M, van der Mark P, Ayres DL, Darling A, Höhna S, Larget B, Liu L, Suchard MA, Huelsenbeck JP, 2012. MrBayes 3.2: efficient Bayesian phylogenetic inference and model choice across a large model space. Systematic Biology, 61:539-542.

Sawyer RT, 1986. Leech biology and behaviour. Clarendon Press, Oxford, pp. 1-1065.

Schwarz G, 1978. Estimating the dimension of a model. The Annals of Statistics, 6:461-464.

Tamura K, Peterson D, Peterson N, Stecher G, Nei M, Kumar S, 2011. MEGA5: molecular evolutionary genetics analysis using maximum likelihood, evolutionary distance, and maximum parsimony methods. Molecular Biology and Evolution, 28:2731-2739.

Tanabe AS, 2008. Phylogears v 2.0 [Internet]. Akifumi S. Tanabe, Accessed 20 Jun 2013, <http://www.fifthdimension.jp/>.

Tanabe AS, 2011. Kakusan4 and Aminosan: two programs for comparing nonpartitioned, proportional and separate models for combined molecular phylogenetic analyses of multilocus sequence data. Molecular Ecology Resources, 11:914921.

Yun IB, 1997. Class Hirudinea. In: List of animals in Korea (excluding insects) (Ed., Korean Society of Systematic Zoology). Akademy Press, Seoul, pp. 142-143 (in Korean).

Received July 9, 2013 Revised March 17, 2014 Accepted March 18, 2014 